\title{
ANÁLISE GEOGRÁFICA: RELAÇÕES DO USO E COBERTURA COM A MORFOLOGIA DAS TERRAS A PARTIR DO SENSOR MODERATE RESOLUTION IMAGING SPECYTORADIOMETER (MODIS) E SHUTTLE RADAR TOPOGRAPHY MISSION (SRTM) PARA O OESTE BAIANO, BAHIA, BRASIL
}

\author{
GEOGRAPHICAL ANALYSIS: RELATIONS OF USE AND COVERAGE \\ TO LAND MORPHOLOGY FROM MODERATE RESOLUTION IMAGING \\ SPECYTORADIOMETER (MODIS) AND SHUTTLE RADAR TOPOGRAPHY \\ MISSION (SRTM) FOR WEST BAIANO, BAHIA, BRAZIL
}

Luciel Passos Oliveira* y Mauricio González Pacheco ${ }^{* *}$

\begin{abstract}
El Oeste Baiano se trata de una región localizada en el Estado de Bahía-Brasil, también conocida como "Além São Francisco", esta se tornó la principal frontera agrícola del Estado en las décadas de 1980 y 1990 y principalmente en este inicio del siglo XXI. La región conoció una expansión agropecuaria sin precedentes, debido al crecimiento y la valoración de granos, cultivos perennes y agricultura irrigada, las que produjeron importantes transformaciones del paisaje. Frente a estas cuestiones investigativas, a partir de los avances tecnológicos que marcan el inicio del siglo XXI, como la observación de la Tierra por Sensoramiento Remoto (SR) empleando satélites, presentan alternativas interesantes para el desarrollo científico de este campo de conocimiento. Esta pesquisa tiene como objetivo identificar y analizar la espacialización de los fenómenos relacionados con la cobertura y uso de la tierra en el oeste del estado de Bahía, empleando datos del sensor orbital MODIS y del SRTM, con el fin de contribuir con la comprensión de las cuestiones ambientales y proponer acciones que visen en la mejora de la preservación y la conservación de los recursos naturales en la región. Después del tratamiento de los datos e informaciones por medio del procedimiento de PDI y la consecuente elaboración de las formas de representación de los fenómenos antrópicos y naturales relacionados con el uso y cobertura de las tierras en el oeste de Bahía permitieron un panorama de las relaciones entre el uso antrópico y la previsión de recursos naturales.

Palabras claves: Agricultura, Sensoramiento Remoto, Río San Francisco.
\end{abstract}

The West Bahia, is a region located in the State of Bahia, Brazil, also known as "Beyond São Francisco", this, became the main agricultural frontier of the state in the 1980s and 1990s and especially in this early 21st century. The region has seen an unprecedented agricultural expansion, due to the growth and appreciation of grains, perennial crops and irrigated agriculture, which have produced important landscape changes. Given these investigative questions, from the technological advances that mark the beginning of the 21st century, such as the observation of the Earth by Remote Sensing (SR) employing satellites, provide interesting alternatives for the scientific development of this field of knowledge. This research aims to identify and analyze the spatialization of land cover and land use phenomena in the western state of Bahia, using MODIS or SRTM orbital sensor data, to contribute to the understanding of environmental issues and to propose actions. Aimed at improving the preservation and or conservation of natural resources in the region. After the treatment of data and information through the PDI procedure and the consequent elaboration of the forms of representation of anthropic and natural phenomena related to land use and land cover in western Bahia, it provided an overview of the relationship between anthropic use and resource provision natural.

Key words: Agriculture, Remote Sensing, São Francisco River.

\section{Introdução}

Estudos ambientais vêm ocupando, cada vez mais intensamente, posição de destaque na abordagem geográfica (Santos, 2008). Ainda segundo a autora mencionada anteriormente, desde o início do século passado a relação homem-natureza/meio, tornam-se cada vez mais, cernes de discussões por diversos setores da sociedade, principalmente acadêmicas. No entanto, são poucos os debates sobre o tratamento

\footnotetext{
* Universidade Federal da Bahia, Instituto de Geociências. Rua barão de Jeremoabo, S/N, Campos de Ondina - Salvador- BA, Brasil. Correo electrónico: lucielpassos@gmail.com

** Universidad de Tarapacá, Departamento de Ciencias Históricas y Geográficas, Arica, Chile.

Correo electrónico mauriciogparica@gmail.com
} 
que a ciência geográfica pode oferecer as questões ambientais afirma Carlos (1991). Porém, desde o final das últimas décadas, notamos um avanço das pesquisas geográficas principalmente almejando relacionar as questões ambientais, principalmente aquelas relacionadas com a apropriação dos recursos naturais pela sociedade. Neste estudo, traremos a luz das discussões, a questão das atividades agropecuárias e da vegetação de cerrado como uso e cobertura da terra e a possibilidade de relacionamento com aspectos morfológico do revelo.

As atividades agropecuárias, caracterizam-se como um dos principais agentes de mudanças da paisagem no interior do estado da Bahia, principalmente no oeste do estado, uma região caracterizada por integrar as novas "fronteiras agrícolas" do Brasil (Filho,1989). Localizado na região limítrofes ao sul com o estado de Minas Gerais, ao oeste com Goiás e Tocantins, ao norte com o Piauí, sendo que no estado da Bahia, ocupa a porção do "Além São Francisco", ou a porção correspondente a margem esquerda do Rio, conforme a Figura 1 na página seguinte. Para Mendonça (2006), o Oeste Baiano se tornou a principal fronteira agrícola do Estado nas décadas de 1980 e 1990. A região conheceu uma expansão agropecuária sem precedentes, em razão do crescimento e da valoração de grãos, cultivos perenes e agricultura irrigada, as quais produziram importantes transformações da paisagem. Segundo os autores Costa e Mondardo (2013), Alysson Paulineli, engenheiro agrônomo, ex-ministro da fazenda durante o governo do general Ernesto Geisel (1974 a 1979), foi o principal responsável pelo desbravamento do cerrado baiano, através da criação da Empresa Brasileira de Assistência Técnica e Extensão Rural (EMBRATER), e da Empresa Brasileira de Pesquisa Agropecuária (EMBRAPA), que possibilitou desenvolvimento de uma agricultura, tropical e competitiva no país, foi esta última que serviu para viabilizar a ocupação dos cerrados principalmente pelos sulistas, tornando a região uma das mais promissoras do Brasil (Costa e Mondardo, 2013, p.1349).

Segundo a revista Agromagazine, edição do mês de setembro de 2012, afirma que, com 16,2 milhões de hectares em área total, o oeste baiano possui 9,1 milhões de ha de bioma cerrado, dos quais 1,9 milhão destinam-se a reservas legais e 1,7 milhão a preservação permanente. Com possibilidade de uso agrícola, estas áreas, soma-se a um total de 5,5 milhões de ha, enquanto 4,6 milhões destes registram boa pluviosidade (Agromagazine, 2012, p.19). No oeste do estado, a agricultura encontrou terreno fértil considerando aspectos pedológicos, geomorfológicos, climáticos e hidrográfico para o seu crescimento e expansão (Donzeli et al. 2003; Filho, 1989; Mendonça, 2006).

De acordo com o Censo Agropecuário de 2017, do Instituto Brasileiro de Geografia e Estatística (IBGE, 2017), o Oeste Baiano, também se transformou em um dos mais importantes geradores de riquezas agrícolas, a exemplo de produtos como algodão herbáceo, este, apresentando um rendimento médio $17,8 \%$, desta forma, responsável por $27,2 \%$ da produção nacional (IBGE, 2017). No oeste do estado, a paisagem natural é caracterizada pelo ecossistema de Cerrado, ao longo das últimas décadas, este ecossistema, vem sendo suprimido em detrimento das áreas de cultivos de algumas commodities agrícolas (soja, milho e algodão). Esta produção é bastante valorizada pelo mercado financeiro interno e externo, ao longo dos últimos 30 anos, a região vem se tornando grande polo de produção agropastoril (Mondardo, 2010).

O Oeste Baiano encontra-se geologicamente na unidade do Grupo Urucuia, abrangendo 86,8\% da área; caracteriza-se por depósitos aluvionares e coberturas dentrito-lateríticas (CPRM, 2008). Os solos são predominantemente Latossolo Vermelho-Amarelo, Neossolo Quartzarênico e solos Hidromórficos associados às veredas. Os solos, em geral, são constituídos por baixa fertilidade, variando de profundos a muito profundos (Moraes, 2003). Segundo Batistella et al (2002), duas estações climáticas são bem definidas na área de estudos: a estação seca e fria (maio a setembro) e a estação chuvosa e quente (outubro a abril). Sua posição geográfica assegura temperaturas elevadas durante boa parte do ano em razão da forte radiação solar. As temperaturas médias máximas e mínimas da região variam entre $30^{\circ} \mathrm{C} \mathrm{e} 20^{\circ} \mathrm{C}$, respectivamente. A pluviosidade anual varia no sentido leste-oeste de $800 \mathrm{~mm}$ a $1600 \mathrm{~mm}$, concentrando-se nos meses de novembro a março (Batistella et al., 2002). Estas características ambientais proporcionam aspectos único da paisagem do Oeste Baiano, ao compara-las com o restante do estado.

A partir dos aspectos ambientais favoráveis ao desenvolvimento agropecuário, a ocupação "mal planejada", em outras palavras, "organizada de maneira não equilibrada", sem uma visão conservacionista ou de sustentabilidade dos recursos 
naturais existente, como foi feita no passado, gerou grandes prejuízos ao meio ambiente local e regional, como, por exemplo, alteração do regime hídrico, supressão excessiva da vegetação e aumento exagerado da erosão de solo (Alves et al., 2009). $\mathrm{O}$ crescimento econômico da região, implicou em mudanças drástica na paisagem, essas mudanças caracterizam-se principalmente pela supressão da cobertura vegetal nativa (Cerrado) por áreas de cultivos e de pastoreio, além de submeter grandes extensões de áreas naturais a riscos de erosão, devido ao desflorestamento sem controle. O Oeste baiano corresponde a uma considerável porção territorial do estado da Bahia, conforme a Figura 1 a seguir.

Diante desse cenário, os recursos materiais e metodológicos para investigações no campo cientifico são variados, dentre os quais destacaremos o Sensoriamento Remoto (SR) e suas operações a exemplo do Processamento Digital de Imagens
(PDI) (Borges et al., 2007; Panquestor et al., 2004; Hermuche et al., 2002). O SR pode ser descrito como um conjunto de tecnologias, que permite a obtenção de dados espaciais e temporais da superfície terrestre (Florenzano, 2007; Novo, 1992). Neste sentido, o SR, representa uma ciência, que tem por objetivo adquirir informações sobre objetos ou fenômenos na superfície da terra sem contato direto com estes (Jensen, 2009). Neste contexto, o processamento digital de imagens de satélite provou ser uma ferramenta importante na detecção de e avaliar as mudanças no uso e ocupação do solo, com o uso de algoritmos que se destacam para fins de classificação ou isolamento do fenômeno que você deseja estudar (Herrera, 2004). Com o desenvolvimento das técnicas de SR, a problemática ambiental vem sendo caracterizada com maior generalização e amplitudes nos últimos anos. Assim, a aplicação desta ciência para alguns, e uma técnica para outros, permite uma visão de "conjunto" ou sistêmica da

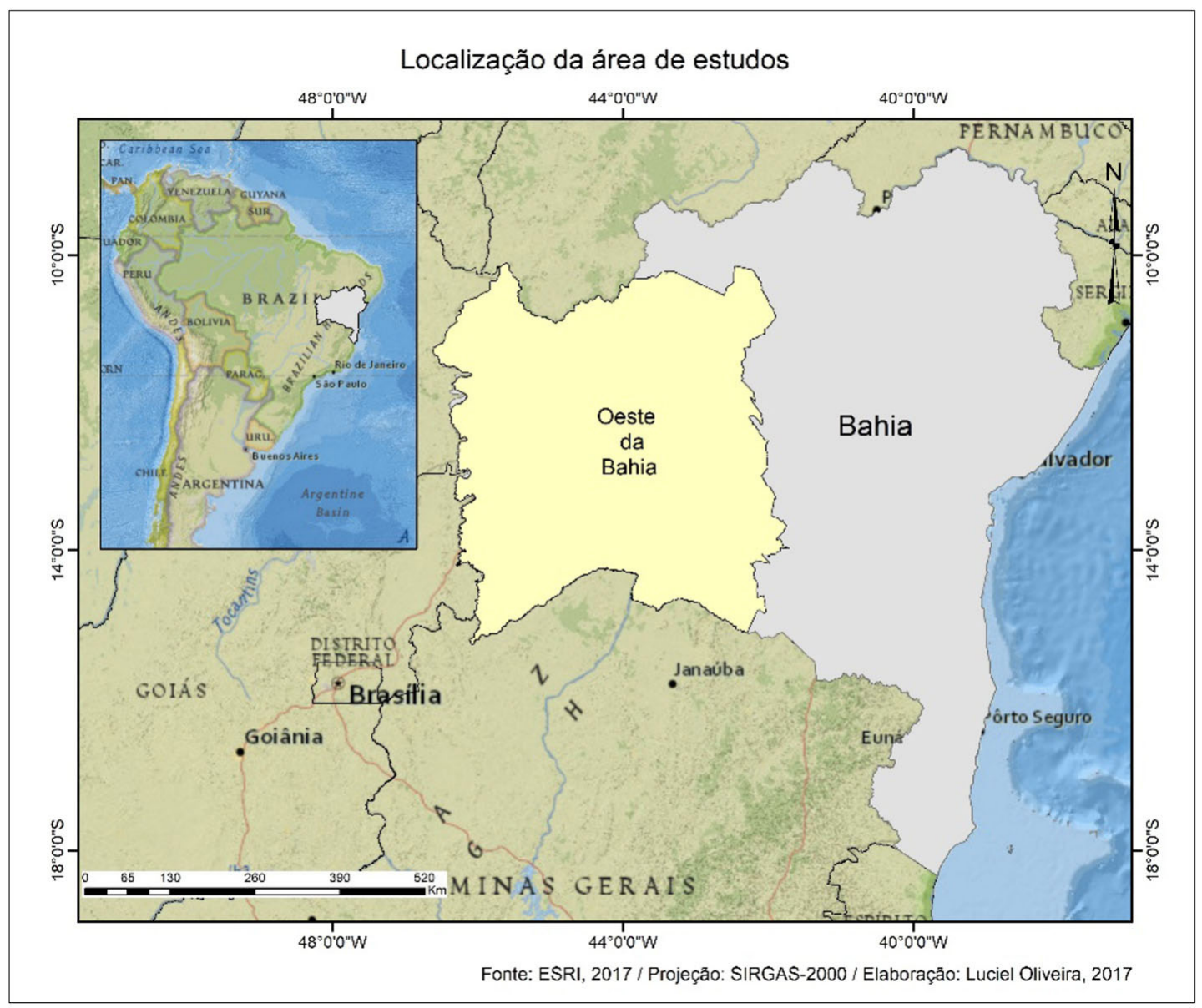

Figura 1. Localização do oeste baiano no contexto sul-americano. Fonte: Elaboração própria. 
paisagem da área de estudos deste trabalho (Oeste da Bahia).

O SR através do PDI, possibilita identificar e classificar as feições registradas nas imagens realizadas por sensores remotos abordo de plataformas orbitais (satélites artificiais), segundo Corrêa (2010), os satélites podem ocupar diversos tipos de órbitas e finalidades (Santos e Gomes, 2010; Rencz e Ryerson, 1999). Os dados dos satélites, possibilitam uma visão de totalidade da superfície, estas tecnologias, já permitem uma imagem relacionada a uma área com dimensões inalcançáveis caso fosse realizada por outras alternativas sub-orbital como aerofotogrametria e outras técnicas de registro (Gonzalez e Woods, 2002). Em par as aplicações, empregando os sensores remoto também se emprega recursos computacionais (pré-processamento, processamento e pós-processamento), software e algoritmos capazes de processar os dados e informações espacial. O aumento no uso de imagens obtidas por sensores localizados nos satélites, aumentou significativamente desde a ocorrência do Furacão Camille em 1969, conseguindo evidências de mudanças na superfície da Terra (Zavala, 2004). O uso e a aplicação dos Sistemas de Informação Geográfica (SIG) evoluiu drasticamente ao longo dos últimos anos, alcançar hoje um papel essencial em nosso sociedade (Silva, 2004).

A partir das bases teóricas sobre as questões ambientais e geográficas, além dos recursos geotecnológicos disponíveis (dados e informações espaciais, hardwares e softwares), esta pesquisa possui como objetivo, identificar e analisar a espacialização dos fenômenos relacionados com a cobertura e uso da terra no oeste do estado da Bahia, empregando dados do sensor orbital MODIS e do SRTM, a fim de contribuir com o entendimento das questões ambientais e propor ações que visem melhorar a preservação e ou conservação dos recursos naturais na região.

\section{Materiais e Métodos}

Para realização dos trabalhos foi necessário o levantamento dos dados (rasters e vetores). Os dados raster foram adquiridos através dos serviços de distribuição de dados e informações ambientais do governo norte americano através das agências: United States Geological Survey (USGS) e National Aeronautics and Space Administration (NASA). Sendo uma imagem multiespectral do sensor
Moderate-Resolution Imaging Spectroradiometer (MODIS) e um imagem de radar do projeto Shuttle Radar Topography Mission (SRTM). Este projeto, foi realizado durante a missão do ônibus espacial Endeavour em fevereiro de 2000. A Missão Topográfica Radar Shuttle é uma missão espacial para obter um modelo digital do terreno (MDT) das zonas da Terra entre os paralelos $56^{\circ} \mathrm{S}$ e 60 ${ }^{\circ} \mathrm{N}$, de modo a gerar uma base completa de cartas topográficas digitais terrestre de alta resolução. Contribuiu para o estudo do Relevo do Brasil.

Os dados vetoriais empregados nesse estudo foram adquiridos junto ao Instituto Brasileiro de Geografia e Estatística (IBGE) e Instituto Brasileiro de Meio Ambiente (IBAMA) através do Sistema Compartilhado de Informações Ambientais (SISCOM). Estes dados vetoriais caracterizam-se como limites municipais, estaduais e hidrografia. Os dados rasters empregados são imagens. O datum e projeção utilizados foram o SIRGAS-2000 e UTM, assim atendendo ao padrão cartográfico atual no Brasil (CPRM, 2008; IBGE, 2009). Os dados vetoriais obtidos a partir do IBAMA, SISCOM e IBGE originalmente possuíam projeções "Córrego Alegre" e "WGS-84 Sul", os dados do USGS tinha originalmente a projeção "WGS-84 Norte". O processo de conversão para o padrão oficial brasileiro (SIRGAS-2000) (IBGE, 2009), foi realizado pelo software QGIS, empregando o recuso de conversão em Lotes, uma vez que esta técnica (operações em Lotes) possibilita uma uniformização e minimização das possibilidades de erros durante o processo de conversão.

Os dados vetoriais foram utilizados para delimitação da área compreendida como oeste baiano, através das malhas municipais e consequentemente geração do polígono (mascara) para recorte da imagem MODIS. A máscara compreendeu ao polígono correspondente a área dos municípios do oeste baiano a partir do "além são Francisco" (margem esquerda do Rio São Francisco até os limites estaduais com Goiás, Tocantins ao oeste e Minas Gerais ao Sul). Foi utilizado o recurso "Dissolver" das ferramentas "Vetores" no software QGIS

Para os dados rasters foi realizado a composição cor simulada Red/Gree/Blue (RGB) da imagem MODIS atendendo a ordem de RGB-621, onde a banda 6 com pixel de $500 \mathrm{~m}, 1$ e 2 com $250 \mathrm{~m}$. A composição das bandas e geração da imagem RGB foi realizada também no software QGIS. Foram realizados testes com valores de contraste 
que variaram de $15 \%$ a $30 \%$, o valor definido como mais apropriado foi $23 \%$, quanto a saturação da imagem, foi utilizado valores de $1 \%$ a $50 \%$, o valor mais apropriado foi $23 \%$. A utilização dos produtos MODIS possibilitaram a cobertura de toda a extensão da área investigada (Oeste da Bahia), desta forma, não ocorrendo necessidade de mosaicos de cenas.

A imagem empregada no estudo, corresponde ao dia 13 de setembro de 2016 foi tomada as $10 \mathrm{~h} 30 \mathrm{~min}$ (horário de passagem pelo equador) em uma orbita no sentido polar (norte-sul) e com revisita em um ou dois dias (Acharya e Ray, 2005). O período correspondente ao mês de setembro implica em uma estação com altas temperaturas, baixa umidade relativa do ar e baixa pluviosidade. Nesta época também ocorre o maior número de áreas queimadas. A composição RGB-621 (Figura 2) possibilitou a interpretação do uso e cobertura das terras de maneira mais clara que as outras realizadas durante os testes e exercícios. Esta composição evidenciou os principais aspectos da paisagem da região, destacando a grande extensão das áreas antropizadas, caracterizadas pela agropecuária e seus processos consequentes a exemplo de queimadas, exposição do solo e substituição de cobertura vegetal nativa. A composição também sinalizou a presença de áreas com remanescentes de vegetação nativa, principalmente cerrado e vegetação de transição entre caatinga e cerrado.

Após a composição RGB, foi realizado a classificação da imagem RGB-621 do sensor MODIS foi realizada empregando o método supervisionado, onde ocorreu a coleta de amostras pixelares em forma de polígonos aleatórios ao longo da composição (Crosta, 1993; Jähne, 2002). Para esta etapa dos trabalhos, foi utilizado o complemento do QGIS denominado "Semi-Automatic Classification Plugin" (SCP plugin), este plugin, possibilita operações de classificação de imagens através do método automatizado e semi-automatizado. Para esta pesquisa, utilizamos

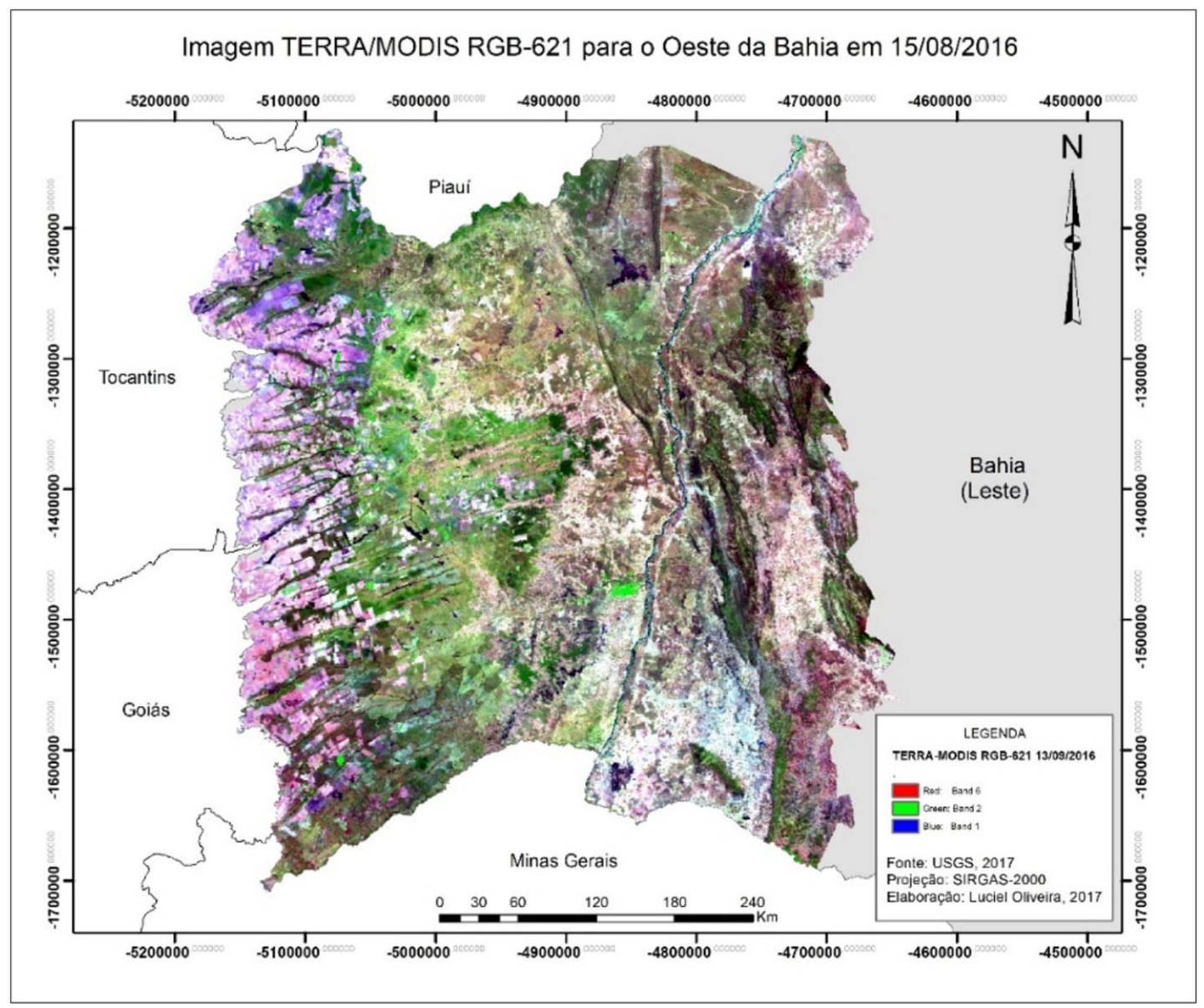

Figura 2. Imagem RGB de referência trabalhada. Fonte: Elaboração própria. 
o método semi-automatizado, caracterizado pelas coletas de amostras de pixels na imagem.

Foi definido previamente cinco classes de uso e cobertura das terras na imagem, foram elas: Agricultura; Agropecuária; Áreas de Silviopastoril; Vegetação densa (Cerrado); Cicatrizes de queimadas e/ou Sombras do relevo. Esta última (Cicatrizes ou Sombras) foi incorporada em uma única classe, visto que os valores espectrais dos pixels possuíam grande proximidade. O método de classificação escolhido foi o de Máxima Verossimilhança (MaxVer), muito usado nos trabalhos de Sensoriamento remoto. Neste método, a distribuição das classes de uso e cobertura das terras é considerada como sendo gaussiana ou normal, isto é, objetos pertencentes à mesma classe tendem a possuir resposta espectral próxima à média de valores para aquela classe (Ribeiro, et al., 2007; Jähne, 2002).

Este método, considera a distância média dos valores correspondentes aos pixels, fazendo uso dos parâmetros estatísticos de distribuição destes pixels dentro de uma determinada classe (Crósta, 1993). Para uma classificação adequada com o MaxVer é importante a escolha de um número razoável alto de pixels para cada amostra coletada para o treinamento da classe, sendo que estes devem possuir uma distribuição estatística próxima da distribuição normal (Crósta, 1993). Ainda segundo Crósta (1993), este método de classificação parte do pressuposto que o usuário conheça previamente a área analisada, bem com a distribuição das classes, para que desta forma, quando da aplicação da classificação, a seleção de amostras de treinamento possa ser o mais eficiente possível (Ribeiro, et al., 2007; Acharya e Ray, 2005).

Para a classificação da área correspondente ao Oeste da Bahia foram coletadas uma média de 85 amostras para cada classe, sendo que este número (85) compreende a média $10 \%$ de cada classe na imagem RGB. O procedimento de coleta das amostras na imagem, ocorreu a partir da leitura e interpretação da mesma, de maneira dá ênfase aos

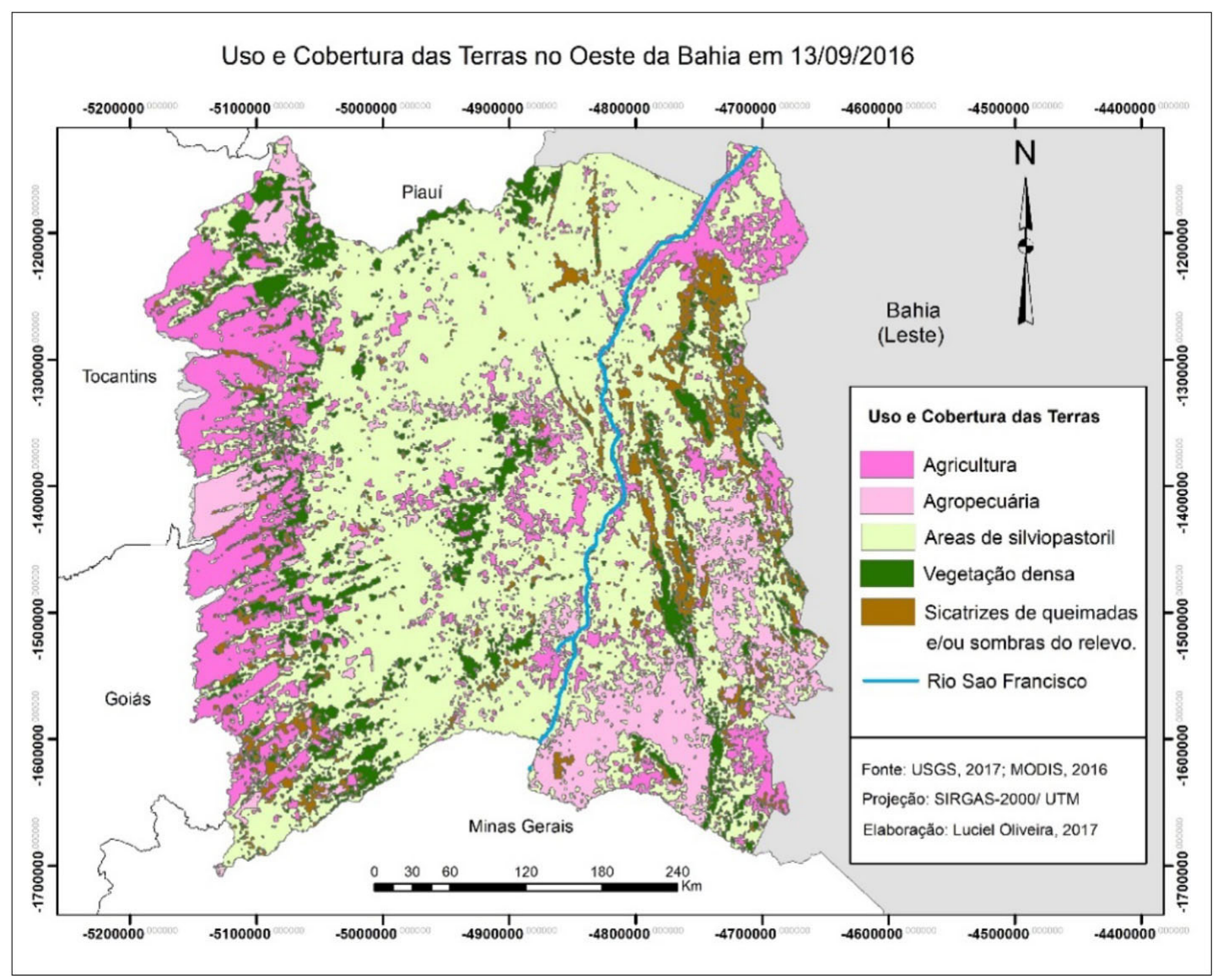

Figura 3. Mapa de uso e cobertura das terras para o oeste da Bahia. Fonte: Elaboração própria. 
pontos onde concentravam-se maiores concentrações de pontos correspondentes a classe definida. Nesta etapa foi considerado um acerto com variação de $70 \%$ a $80 \%$ do conjunto de classe de uso e cobertura da terra na imagem. Para o formato dos arquivos correspondentes as amostras de treinamento do classificador, optou-se pelo shapefile (.shp). O mapa de uso e cobertura das terras (Figura 3 ) corresponde ao resultado final da classificação a qual foi realizada no programa QGIS Desktop 2.18.12.

Após a etapa de classificação da RGB e consequente geração do mapa de uso e cobertura das terras, a etapa seguinte foi o tratamento da imagem de radar SRTM a qual possui um pixel de $90 \mathrm{~m}$. A imagem SRTM possibilita o Modelo Digital de Terreno (MDT) o qual possibilita a compreensão das formas do relevo da área investigada. Para esta pesquisa o MDT foi classificado de acordo a hipsometria da área qual possui cota mínima $371 \mathrm{~m}$ nas áreas de vale próximo ao Rio São Francisco, até a cota máxima $1981 \mathrm{~m}$ nos topos das serras da face oeste (sota-vento) da Chapada Diamantina (Figura 4).

A partir do processamento dos dados SRTM, foi gerado um MDT tridimensional para a área de estudos (MDT-3D). A visualização tridimensional das formas e objetos da paisagem da região imageada pelos sensores, possibilitou a visualização volumétrica dos objetos constituintes da paisagem. A visualização volumétrica da forma do terreno somado ao mapa de uso e cobertura das terras, possibilita a "visão de conjunto" e/ou "análise integrada" pela ciência geográfica. As formas do relevo da área de estudos (oeste baiano), apresentam sensibilidade quando submetidas a visualização tridimensional. Isto ocorre, devido as grandes planícies constituintes da paisagem da região e as relativas baixas altimetrias distribuídas, desta forma, implicam em uma necessidade maior de aumento do exagero vertical.

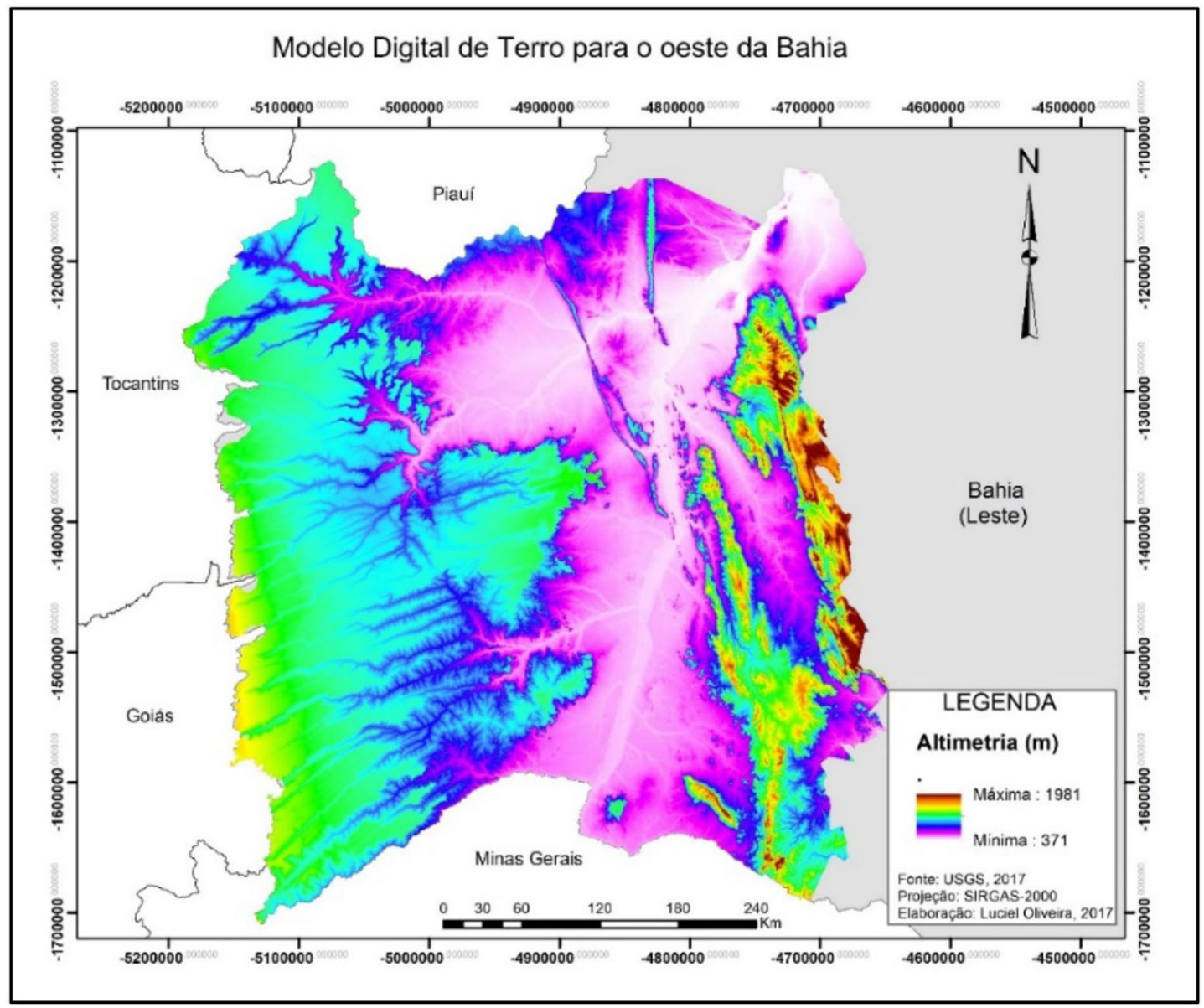

Figura 4. Caracterização altimétrica da área de estudo. Fonte: Elaboração própria. 
Nesta etapa (modelagem tridimensional), foi utilizado como ferramenta/recurso de software o complemento denominado plugin Qgis2threejs no ambiente do software QGIS, partindo do pressuposto que as etapas de aquisição de dados e processamento, seria utilizado recursos gratuitos. $\mathrm{O}$ complemento Qgis2threejs serve para modelagem em 3D e visualização volumétrica. A ferramenta permite a visualização de um modelo em três dimensões em navegadores de internet que suportem a tecnologia WebGL, o qual permitiu uma visão com maior amplitude da relação forma do terreno e disposição/espacialização ao longo da área de estudos (Figura 5).

O processamento utilizado no Modelo Digital de Terreno, possibilitou a confecção do mapa de altimetria e morfologia da área delimitada para estudo (Felgueiras, 1987). Através deste mapa, foi possível iniciar o processo de modelagem do uso e cobertura das terras e sua relação com a formato do relevo (Destri, 1987; Crósta, 1993). Desta forma, possibilitando uma interpretação da espacialização dos fenômenos ligados ao uso e cobertura das terras no oeste da Bahia. Após o trato dos dados e informações, por meio do processamento digital de imagens (PDI) e da modelagem 3-D do uso e cobertura das terras, foi possível ter uma visão de conjunto das relações entre o uso antrópico e a disposição dos recursos naturais na área de estudos.
A visualização volumétrica das formas de relevo e a sua combinação com o uso da terra possibilitou entender as relações entre os fatores ou características especiais que levam a manutenção do uso da terra assentados sobre determinadas formas de relevo. No caso deste estudo, a grande área de planalto.

\section{Resultados e discussões}

A visão tridimensional do uso e cobertura das terras no oeste baiano, possibilitou identificar as feições localizadas na porção do extremo oeste, como uma área de planalto, com características imprescindíveis para a realização da agricultura de precisão voltada a produção de sequeiros e commodities agrícolas, bastante valoradas no mercado financeiro nacional e internacional. Foi possível confirmar as feições de planalto na paisagem, e o quanto é importante e favorável a agricultura de precisão responsável pela alta produção e consequente geração de riquezas, conforme defende Mondardo (2010). No entanto, este avanço na atividade agrícola, ocorre também pela fertilização artificial dos solos, uma vez que estes solos em áreas de planaltos possuem baixa fertilidade para a agricultura segundo (Moraes, 2003).

A partir da leitura do MDT gerado para a região, foi possível notar a grande planície a qual a agricultura se desenvolveu e também possibilita

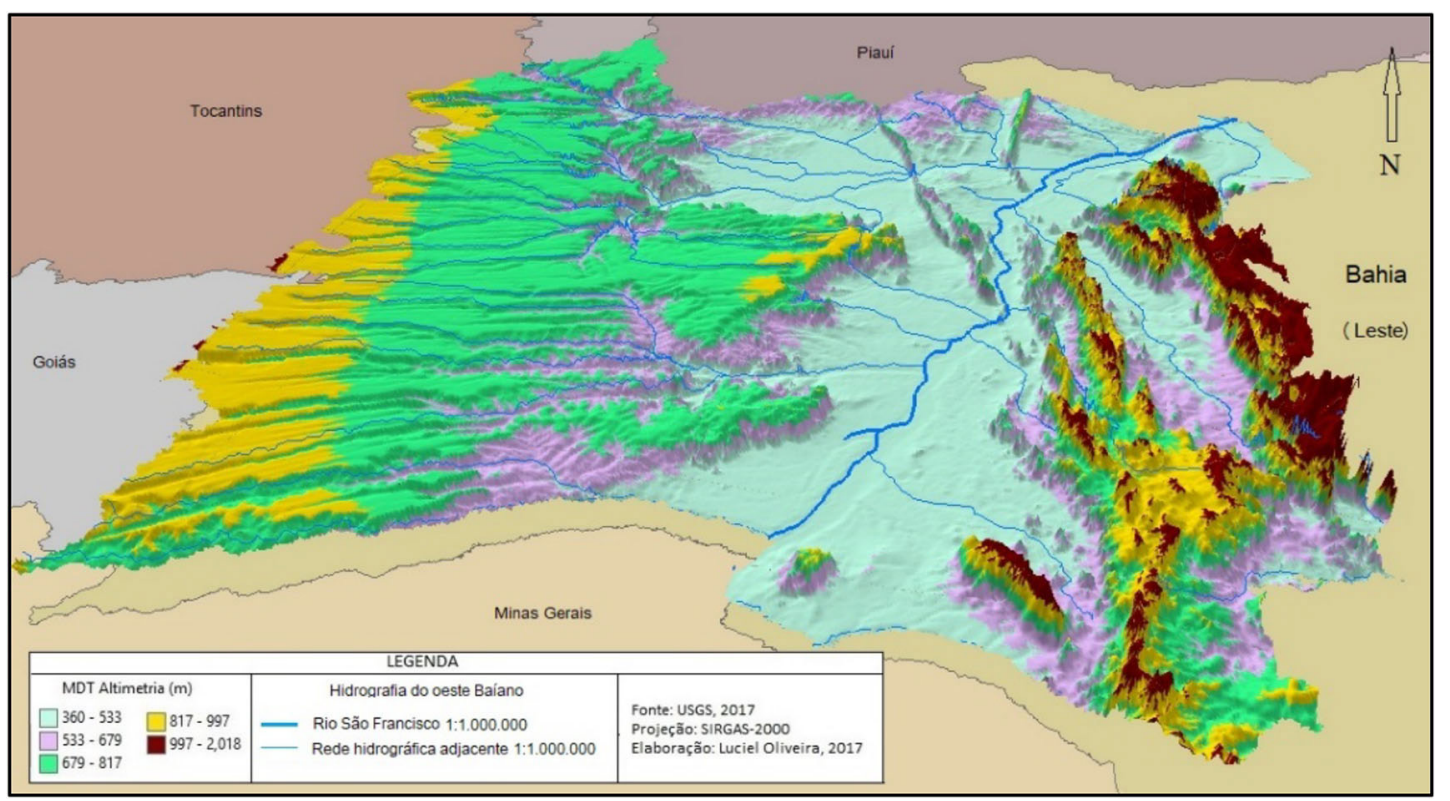

Figura 5. Perspectiva 3D da altimetria do oeste da Bahia. Fonte: Elaboração própria. 
continuar se desenvolvendo, através da ampliação das áreas cultivadas sobre as áreas de vegetação nativa, porém localizadas em terrenos planos favoráveis a mecanização. O MDT da área estudos na perspectiva 3D, também possibilitou visualizar a organização da rede de drenagem e sua espacialização ao longo do oeste baiano. Durante os processos de expansão das atividades agrícolas na região, os recursos hídricos, principalmente os rios e córregos, sofrem com processos de erosão e consequentemente assoreamentos. A rede de drenagem ocupa os veios e áreas mais rebaixadas do relevo cravado ao longo da extensão grande área plana (Figura-5 anterior). A disposição da rede de drenagem ao longo do planalto, possibilita a alimentação das atividades agrícolas através da irrigação uma vez que a grande área plana favorável a agricultura encontra nos canais fonte de abastecimento para os seus pivôs responsáveis pela produção em algumas localidades (Soille, 1988). No entanto, o abastecimento hídrico das atividades agrícolas pode ser comprometido, devido ao processo de assoreamento dos córregos, canais e rios.

Os trabalhos com o MDT (Felgueiras, 1987), também permitiram a elaboração de uma linha transecto, capaz de fornecer uma perspectiva de perfil de um ponto extremo a outro no sentido oeste-leste da área investigada (Destri, 1987). Este transecto, permitiu visualizar as variações altimétricas no que diz respeito a drenagem e o impacto do fluxo hidrográfico nas áreas mais rebaixadas do relevo onde localiza-se a calha principal do Rio São Francisco, sendo este o receptor maior do fluxo de drenagem do oeste baiano (Figura 6 a seguir). O uso da linha se transecto como parâmetro para entendimento da dinâmica da morfologia e sua relação com os usos da terra, possibilita entender que a paisagem é mosaico plural com formas que mesmo semelhantes, implicam em uma resposta complexa as dinâmicas das interferências antrópicas na região.

A linha de transecto gerada a seguir mostra a influência da morfologia do terreno com a rede hídrica a qual fornece água para as atividades agrícolas baseadas na irrigação por meio de pivôs centrais. Além indicar que o volume de drenagem da região tende ao sentido Oeste-Leste (W-E), ou do planalto para o vale do rio São Francisco, onde torna-se o receptor dos fluxos drenados do oeste baiano. Estes fluxos são caracterizados desde a sedimentos arenosos carrilados pelas correntezas até substâncias nocivas provenientes do uso indiscriminado de pesticidas, fertilizantes e demais substâncias empregadas na agricultura na região. A Figura 6 a seguir apresenta a linha de transecto junto ao mapa altimétrico da região com as medidas em metros, em paralelo a escala de distâncias em quilômetros.

A elaboração do MDT-3D e da linha transecto altimétrico ao serem incrementados ao mapa de UCT, possibilitou visualizar a disposição do uso e cobertura das terras de acordo com a altimetria da área. Foi possível verificar que as áreas do extremo oeste da Bahia, possuem uma relação intima entre morfologia e uso da terra, principalmente pelo favorecimento da implantação da agricultura mecanizada em grande extensão para fins de produção das commodities. Nesta modalidade, o maquinário envolvido necessita de áreas aplainadas para poder circular de maneria mais rápida e eficiente. As áreas de transição de cotas altimétricas, principalmente nas imediações do vale do Rio São Francisco, possui resquícios de vegetação densa e também pontos de atividades agrícolas de uso intensificado próximos ao do oeste baiano, conforme o mapa de UCT em uma perspectiva tridimensional a seguir (Figura 7).

A partir da ilustração anterior (Figura 7), nota-se também que as áreas de agricultura intensificada, implicam em riscos para a vegetação nativa. Este risco, caracteriza-se pelo desflorestamento (perda da vegetação nativa) e aumento das possibilidades de surgimento de processos erosivos no solo. As áreas de risco no oeste baiano, são evidenciadas por pontos de tensão sinalizados na Figura 7 anteriormente, como pontos de "vizinhanças" entre agricultura, vegetação densa e cicatrizes de queimadas, estas feições estão evidentes na poção sudoeste da área de estudos, próximos aos limites dos estados de Goiás e Minas Gerais.

O mapa de UCT-3D (Figura 7) anterior, permitiu em uma perspectiva tridimensional a elaboração de uma nova linha transecto visando caracterizar o perfil topográfico e a sua relação de uso e cobertura. Inicialmente, no sentido oeste-leste em uma faixa de 0 até $75 \mathrm{~km}$ existe uma intensificação da agricultura, neste trajeto foi possível identificar uma faixa de transição caracterizada por vegetação densa entre $75 \mathrm{~km}$ a $95 \mathrm{~km}$. As áreas de silvipastoril, ocupam a faixa de $100 \mathrm{~km}$ a $170 \mathrm{~km}$. Entre $180 \mathrm{~km}$ a $240 \mathrm{~km}$ existe uma intercalação entre agricultura, vegetação densa, agricultura e atividades silvipastoril. Entre $225 \mathrm{~km}$ e $250 \mathrm{~km}$ localiza-se uma área de transição do planalto para a planície (vale do Rio São Francisco - RSF), nesta área as bordas do topo 


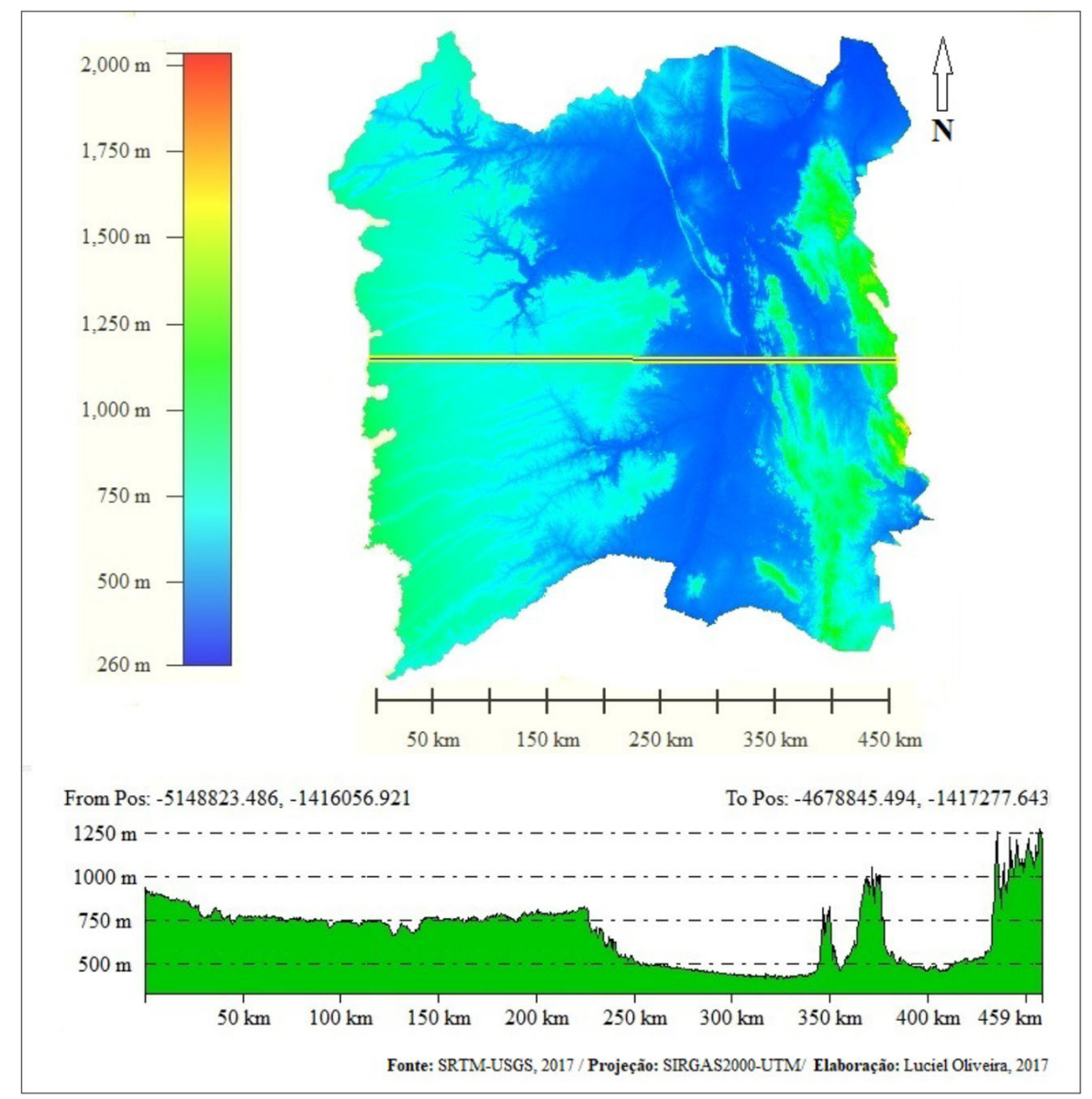

Figura 6. Perfil topográfico do oeste baiano com transecto altimétrico em pontos extremos da área de estudos. Fonte: Elaboração própria.

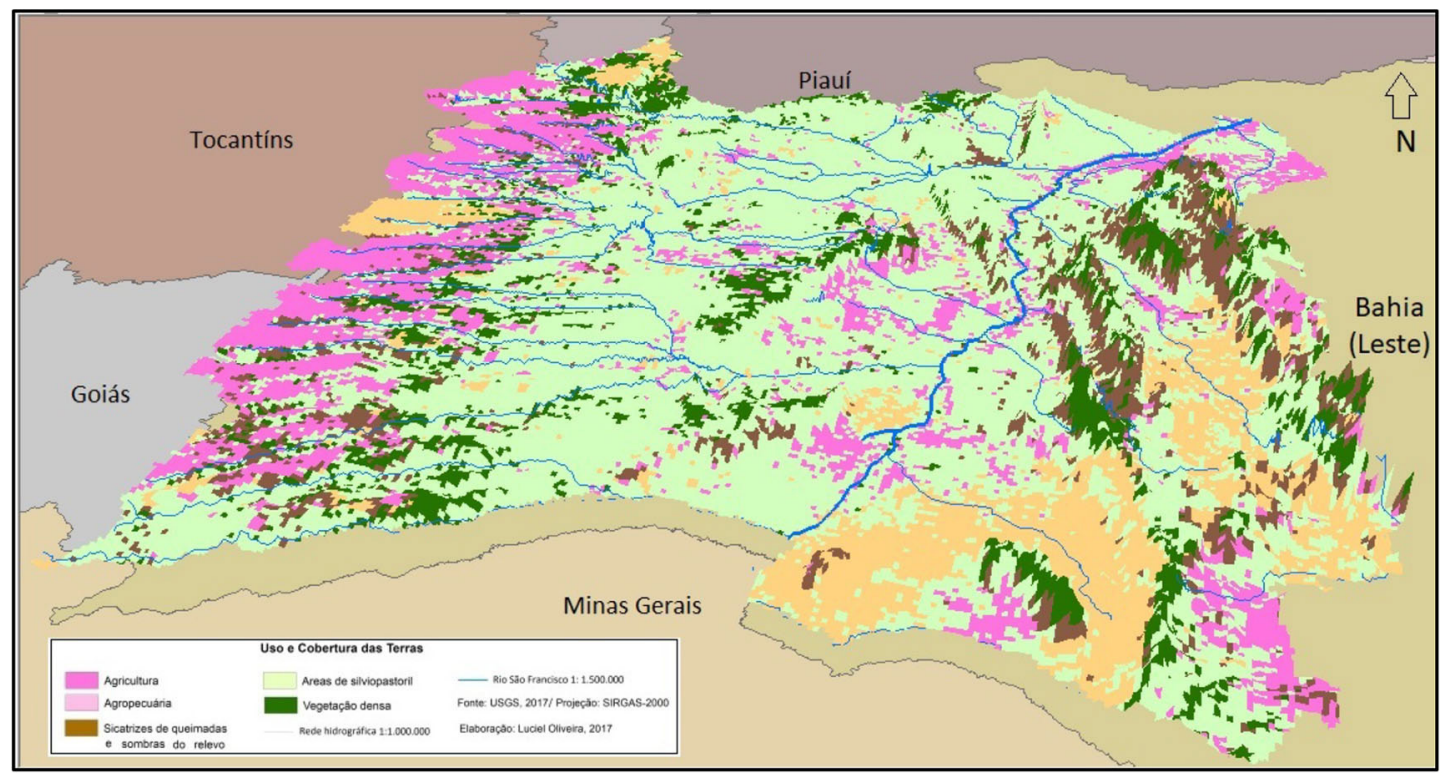

Figura 7. Uso e cobertura das terras do oeste baiano em perspectiva 3D. Fonte: Elaboração própria. 


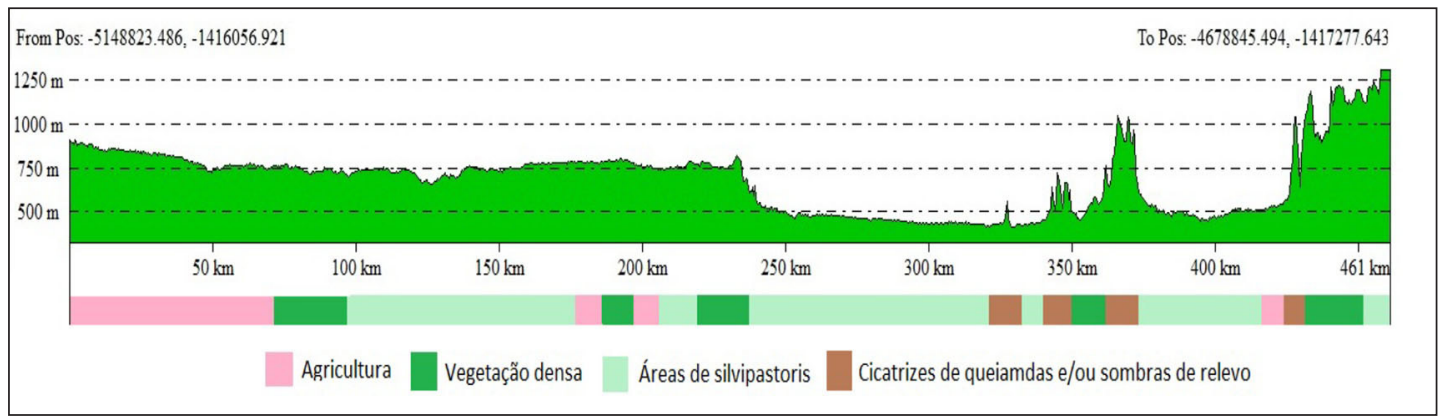

Figura 8. Transector do uso e cobertura das terras no oeste da Bahia. Fonte: Elaboração própria.

do relevo encontra-se coberta por vegetação densa enquanto a encosta e maior parte da planície do Rio é marcada pela atividade silvipastoril (Figura 8).

Na área da planície do RSF, foi possível identificar as cicatrizes de queimadas e também as sombras de relevo, sendo que neste estudo, essas duas classes foram incorporadas como já explicado na metodologia. As áreas de cicatrizes de queimadas encontram-se a distancias aproximadas de $330 \mathrm{~km}$ (sentido oeste-leste) intercaladas por atividades de silvipastoril e vegetação densa em pontos com elevação topográfica saliente (Figura-6). Em uma distância de 400km do início do transecto encontra-se o vale do Rio Paramirim, o qual é caracterizado pela presença de atividades de silvipastoris, pontos de agricultura intensificada e queimadas e/ou sombras em decorrência da acentuada inclinação das encostas que constituem o conjunto de serras da Chapada Diamantina a aproximadamente $430 \mathrm{~km}$ de distância do início do transecto conforme Figura 6 anterior.

\section{Conclusões}

Neste estudo, a apropriação de técnicas como o Sensoriamento Remoto (SR) combinados com a utilização dos Sistemas de Informações Geográficas (SIG) e a modelagem tridimensional de dados espaciais, possibilitaram uma visão de conjunto de fenômenos e objetos marcantes no espaço geográfico. A pesquisa possibilitou entender a relação entre a morfologia do terreno e o crescimento de atividades agrícolas de precisão e alto rendimento. Foi possível perceber que o oeste da Bahia, reúne características ambientais capazes de facilitar a expansão das atividades agrícolas, assim como também permite intensificar processos de degradação ambiental, como as perdas de vegetação nativa e esgotamento hídrico. Dentre as características ambientais, as quais consideramos "chaves" para expansão dos empreendimentos agropecuária destacados, está a geomorfologia, a pedologia, além de outras como pluviosidade e etc. As técnicas de observação da paisagem empregado neste estudo (geotecnologias) possibilitaram uma visão de síntese dos aspectos físicos do Oeste Baiano.

O emprego do SR e SIG e da modelagem tridimensional de MDT, possibilitaram a sistematização de um conjunto de interpretações da paisagem de maneira rápida, a qual pode ser aprimorada com o aprofundamento dos trabalhos. A partir dos resultados e discussões deste estudo, a intensificação de ações de fiscalização e controle do desmatamento da vegetação nativa, assim como o monitoramento do crescimento das áreas destinadas a agricultura, atentando principalmente a preservação das reservas ambientais obrigatórias por lei, tendo como base, os parâmetros e determinações da legislação ambiental brasileira.

Recomendamos o monitoramento continuo da paisagem do Oeste baiano, empregando o SR como recurso, afim de identificar os pontos de desflorestamento ilegal, a intensificação dos processos erosivos decorrente do preparo da terra para a agricultura. Para estes trabalhos, aconselhamos o uso dos produtos dos satélites de observação de recursos naturais como a plataforma Terra com o sensor MODIS para alcance da totalidade da área em questão (Oeste Baiano). O uso do MODIS também possibilitou recomendar às investigações pontuais (em áreas menores dentro dos municípios da região) o uso de dados de satélites com escala de detalhamento maior, como exemplo e sugestão deixamos a série LANDSAT, principalmente com o satélite número 8 com sensor OLI com resolução de $30 \mathrm{~m}$. Sendo assim para as duas possibilidades, é possível realizar o monitoramento descrito anteriormente em 
uma escala espacial variável e temporal continua, uma vez que essas plataformas encontram-se em perfeito funcionamento e distribuição de dados gratuitos e acessíveis a toda comunidade cientifica.

O monitoramento geográfico empregando o SR e a modelagem de dados, possibilita a comunidade cientifica acedência assim como os órgãos estatais e as organizações civis dedicadas a conservação dos recursos naturais, um instrumento funcional para suas atribuições e compromissos junto a sociedade e as instâncias judiciais (Poder Público). Lembramos que estudos a exemplo deste, requerem baixo recursos financeiros, uma vez que a maior parte dos dados e informações se encontram gratuitamente, porém requer uma mão de obra especializada a qual a academia (universidades) através de suas instancias (pós-graduação) podem oferecer. É importante a valoração dos profissionais envolvidos nestes trabalhos através do incentivo e estimulo as suas práticas voltadas ao compromisso com a sociedade.

\section{Referência}

Acharya, T., Ray, A. K.

2005 Image Processing-Principles and Applications. John Wiley \& Sons, Inc.

Agromagazine.

2012 Revista Agromgazine, Ed. o4, Oeste da Bahia, setembro de 2012

Borges, M.; Guimarâaes, M.; Miranda, E. E. de; Vieira, H. R.;

Valladares, G. S.; Mangabeira, J. A. de C.

2002 Monitoramento da expansão agropecuária na região Oeste da Bahia. Campinas, SP: Embrapa Monitoramento por Satélite, $39 \mathrm{p}$.

Carlos, A. F. A.

1991 O meio ambiente urbano e o discurso ecológico. In: III Encontro Nacional de Estudos sobre Meio Ambiente. 1991. Londrina. Anais... Núcleo de Estudos do Meio Ambiente. Universidade Estadual de Londrina, pp. 756-766.

Corrêa, I. C. S.

2010 Satélites Artificiais. Museu de Topografia Prof. Laureano Ibrahim Chaf $f e$. Departamento de Geodésia - IG/UFRGS.

Costa, D. H.; Mondardo, M. L.

2013 A Modernização da Agricultura no Oeste Baiano: Migrações Sulistas e Novas Territorialidades. Revista Geonorte. Edição Especial 3, v.7, n. 1, p.1347-1361.

Batistella, M.; Guimarães, M.; Miranda, E. E.de; Vieira, H. R.;

Valladares, G.S.; Mangabeira, J. A. de C.; Assis, M. C.

2002 Monitoramento da expansão agropecuária na região Oeste da Bahia. Campinas, SP: Embrapa Monitoramento por Satélite, 39 p. il.

Crósta, A. P.

1993 Processamento Digital de Imagens de Sensoriamento Remoto, Campinas, SP, UNICAMP, ed. rev.

CPRM,

2008 (Online). Carta geológica do Brasil ao milionésimo. Disponível em < http://www.funape.org.br/geomorfologia/ cap 1/index.php $>$ Acesso em 12/07/2019.

Destri, A.R.

Tratamento de Modelos Numéricos do Terreno (DTM) Obtidos por Processos Fotogramétricos. Dissertação de Mestrado em Engenharia de Sistemas do Instituto Militar de Engenharia, IME, 257 pp.

Donzeli, P. 1.; Moraes, J. F. 1.; Menk, J. R. F.; Fernandez, G. A. V. 2003 Gestão ambiental integrada do bico do papagaio: aptidão agrícola da folha. SB: 22-Z-B, Xambioá, TO

Ribeiro, R. J.C.; Baptista, G. M. M. E Bias, E. S.

2007 Comparação dos métodos de classificação supervisionada de imagem Máxima Verossimilhança e Redes Neurais em ambiente urbano. Anais XIII Simpósio Brasileiro de Sensoriamento Remoto, INPE. Florionópolis, Brasil.

Felgueiras, C. A.

1987 Desenvolvimento de Um Sistema de Modelagem Digital de Terreno para Computadores. Dissertação de mestrado em Computação Aplicada. Instituto de Pesquisas Espaciais. INPE. 243 p.

Filho, Milton Santos.

1989 O Processo de Urbanização no Oeste Baiano. Recife, SUDENE-DPG. PSU-URB.

Florenzano, T. G.

2007 Iniciação em sensoriamento remoto. $2^{\circ}$ ed. São Paulo, SP: Oficina de Textos.

Gonzales, R., Woods, P.

2002 Digital Image Processing. Prentice Hall, 2nd ed.

Herrera, G. V.

2004 "Geomática: integración tecnológica para estudios urbanos", en: Diálogo Andino 23, pp. 23-32.

Hermuche, P. M.; Guimarães, R. F.; Carvalho, A. P. F.; Martins, E. S.; Fucks, S. D.; Carvalho Junior, O. A.; Santos, N. B. F.; Reatto, A.

2002 Morfometria como suporte para elaboração de mapas pedológicos. I bacias hidrográficas assimétricas. Planaltina. DF: Embrapa Cerrados.

IBGE

2009 Instituto Brasileiro de Geografia e Estatística: Coordenação de Recursos Naturais e Estudos Ambientais. Manual técnico de geomorfologia. 2. Ed. Rio de Janeiro.

IBGE

2017 Instituto Brasileiro de Geografia e Estatística: Censo agropecuário 2017: IBGE revela retrato do Brasil agrário, Censo Agropecuário.

Jensen, J. R.; Epiphanio, J. C. N.

2009 Sensoriamento remoto do ambiente: uma perspectiva em recursos terrestre. São José dos Campos, SP: Parêntese. Brasil.

Jähne, B.

2002 Digital Image Processing. Springer-Verlag.

Panquestor, E.K.; Carvalho Júnior, O. A. de; Ramos V. M.; Guimarães, R. F.; Martins, E. de S.

2002 Aplicações de indicadores quantitativos na definição de unidades de paisagem e uso da terra na bacia do rio Corrente - BA. In: Encontro Nacional da Associação Nacional de 
Pós-graduação e Pesquisa em Ambiente e Sociedade. 2. Indaiatuba, v.2, pp. 1-16.

Mendonça, A. J. O.

2006 O potencial de crescimento da produção no oeste da Bahia. Bahia Agrícola, v.7, n.2, abr. pp. 38-46.

Moraes, L. S.

2006 Diagnóstico de uso e ocupação da bacia do Rio de Ondas; barreiras/BA. Bahia Agrícola, v.7, n.2 abr. pp. 38-46.

Mondardo, M. L.

2010 A "territorialização" do agronegócio globalizado em Barreiras - BA: migração sulista, reestruturação produtiva e contradições sócio-territóriais. Revista NERA Presidente Prudente.

Novo, E.M.L.M.

1992 Sensoriamento Remoto: princípios e aplicações. $2^{\circ}$ Ed. Editora Blucher. São Paulo- SP.

Rencz, A. N., Ryerson. R. A. (Eds.)

1999 Manual of Remote Sensing, Remote Sensing for the Earth Sciences. John Wiley \& Sons, Inc. 3rd ed.

\section{Santos, D. M. J.}

2008 Interfaces entre práticas de coleta seletiva do lixo e conceitos lefebvrianos: um estudo sobre a Pituba, SalvadorBA. GeoTextos, vol. 4, n. 1 e 2, pp. 121-142.

Santos, V. H. O.; Gomes, S. R.

2010 Satélites artificiais: Fundamentos físicos e utilidades. IX Congresso de Iniciação Cientifica do IFRN. Tecnologias e inovação para o semiárido. Natal, Brasil.

Silva, J. E.

2004 "Los SIG y su rol en la sociedad: pasado, presente y futuro", en: Dialogo Andino 23, pp. 23-32.

Soille, P.

1988 Modéles Numériques de Terrain et Morphologie Mathématique: Délimitation Automatique des Bassins Versans. Mémoire de Stage. Université Catholique de Louvain-la- Neuve(Belgique).Unité Génie Rural.

Zavala, O. P.

2004 "Aplicaciones de teledetección en el seguimiento del peligro sísmico", en: Diálogo Andino 23, pp. 45-52. 